\section{A NEW SYSTEM

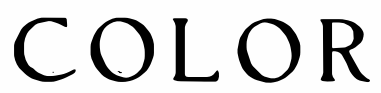

Since the introduction of the Lumiere autochrome color-sensitive plate within the last three years, upon which a composite color picture is made at one operation direct in the camera, quite an impetus has been given to improvements in this line, which will overcome one of the drawbacks of the French process, that is, the difficulty of securing duplicate color photographs except by succesive exposures in the camera.

The new system we are about to describe has this particular feature, that duplicate color pictures can be obtained $a d$ libitum from the first netive obtained in the camera. It has been perfected and simplified by $\mathrm{Mr}$. Frederick $\mathrm{E}$. Ives of this city, and is quite unique in the way certain apparent difficulties are overcome.

The process is based on the merging of the three primary colors, red, blue, and green. It is not quite as simple in operation as the autochrome process, but possesses the following definite advantages over that: The sensitive plates used keep better, developing successfully when several months old, and cost but half as much as the autochrome plates; the positive transparencies are made by a separate process from the finished negatives, thus permitting the making of any number of duplicates; the transparencies transmit number of duplicates; the transparencies transmit
many times as much light as autochromes, and are many times as much light as autochromes, and are
quite free from granularity, so that they are perfectly quite free from granularity, so that they are perfectly adapted for use along with ordinary lantern slides in the lantern, also for use in the stereoscopes; the process also permits of local treatment to modify the colors when and where desired with extraordinary facility, a feature which will be greatly appreciated by the artistic amateur.

A special camera is required to make the triple negatives, but it is very simple, and can be used withou change for all ordinary kinds of photography with plates or films.

When ${ }^{\prime}$ it is desired to make a set of triple negatives for color photography, a "trichromatic plate pack," consisting of three sensitized plates held together as one, is used in the special plate holder instead of a single plate, and is so disposed in the camera after the plate holder has been inserted as to produce by one exposure three negatives, representing the three primary colors. The "plate pack" consists of a redsensitive and a green-sensitive plate with the sensitive or film surfaces in contact, held between a backing card and a blue-sensitive plate which is hinged thereto by a strip of gummed paper. When the pack is inserted in the plate holder the red- and green-sensitive plates are retained by ledges, and are pressed in close contact, film against film, by a spring on the lid, but the blue-sensitive plate is made slightly shorter, so that it falls or passes outward between the ledges. When the opaque slide of the plate holder is withdrawn, in preparing for an exposure, this plate falls or into the camera, resting on the bottom of the latter in a horizontal position at right angles to the other plates. After this a yellow screen plate is dropped down from the camera roof by means of a lever on the exterior as shown in the diagram, and the usual compensating screen is placed over the lens tube. Then the exposure is made by means of the lens shutter, which is said to be about as long as that required for an utochrome plate.

Referring to the diagram, $A$ is the lens having a compensating color screen $B$ attached to it, whic equalizes the exposure for the three images and perfects the color selection. $C$ is a hinged transparent

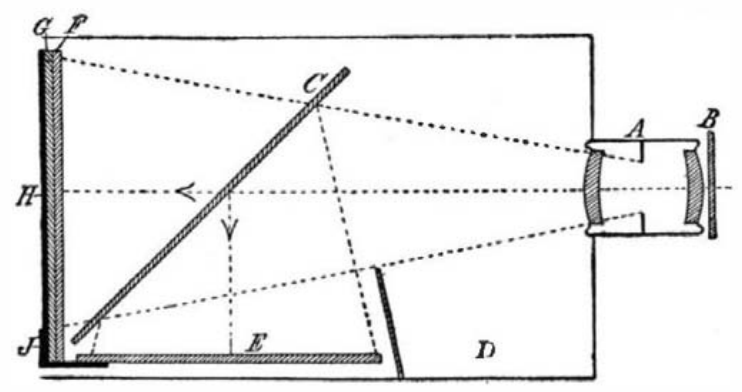

Interior arrangement of camera.

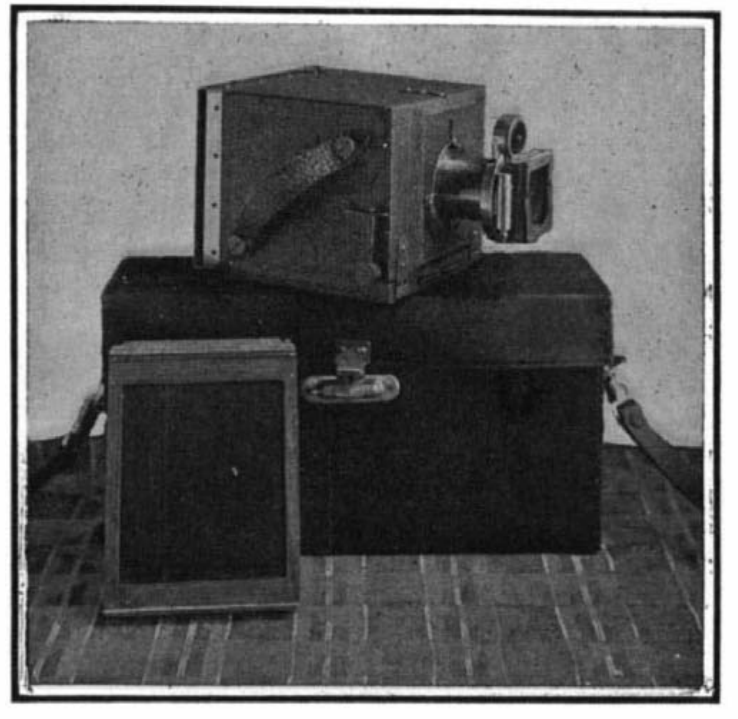

The camera, plate bolder, and carrying case.

yellow glass reflector, and $D$ is a light trap. $E$ is the dry plate sensitive to the blue rays, lying in a horizontal position, which receives the Image reflected downward by the yellow glass reflector $c$. As the lens image passes directly through the reflector $C$, only the green and red rays act on the vertical sensitized plates respectively, $F$ and $G$. The film of $F$ is in contact with the film of $G$, hence the light acts first on the back side of the film $F$, but some of it passes through the film, and impresses the front side of the film on the red-sensitive plate $G$.

After exposure the reflector $C$ is turned upward in contact with the roof of the camera by a knob on the outside; then the plate $\boldsymbol{E}$ is placed in a vertical position against the other plates by means of another lever on the outside (shown in the engraving) and the slide of the plate holder is inserted.

$H$ and $J$ represent an opaque backing card and a flexible hinge attached to the plate $E$, the plate $F$ being loose, but held clamped between $H$ and $E$ when the pack is closed.
THE IVES SYSTEY OF COLOR PHOTOGRAPHY

\section{PHOTOGRAPHY}

The plate holder is inserted at the back of the camera under a ground-glass frame held by springs it the usual way. Focusing is done by moving the lens inwara or outward through a tube on the front.

It is evident from this arrangement that the image on each plate must be exactly the same, but that two of them will be "reversed," one by refleetion and the other because made through the glass side of the plate.

In making positive duplicates on the film, it is only necessary to reverse the position of the print from the positive-positioned negatives to make all three positive prints coincide when bound together between two glass plates to form one harmonious transparent colored picture. The collodion positive film is so thin that picturate registration of the three films is not affected.

The exposed plates are developed by time development as a unit held in a special rack, they being separated open like the leaves of a book in a tank filled with an amidol developer. The resulting negatives show no color, but contain the color record in black and white, and when finished are available at any time for making natural color transparencies.

To make the transparent color prints, the three negatives are placed side by side in a printing frame. A sheet of collodion bearing a coating of bichromated fish glue is laid collodion side down on the negatives, the back of the printing frame put in, and then ex posure made to light through the negatives-about one minute in clearest sunlight. The exposed sheet is then removed from the frame, clamped coated side up on a glass, and developed by washing with water under tap for a few seconds. This gives three graduated low-relief prints which are perfectly transparent, but they are then cut apart and immersed in separate red, blue and green dye baths for a few minutes (the dyes to be furnished in their proper colors), then rinsed off, dried, and superposed in register to make the complete natural color transparency. The same negatives are available for color prints on paper, but the processes for making color prints on paper are not yet nearly so simple and satisfactory as the transparency

The appearance of the camera and plate holder and the case for carrying the apparatus is shown in the illustration. It is quite compact and simple. Examples of these pictures both in the form of lantern slides and stereoscopic transparencies have been shown us, and they possess a most pleasing brilliancy and transparency in coloring just as one would like to see. It should be mentioned that Mr. Ives, the inventor of this system, succeeded in developing and perfecting the half-tone and half-tone three-color processes severa years ago, and may be regarded as one of the pioneers in color photography. For some of these discoveries he was awa Photographic Society of Great Britain, the Elliott Cresson medal of the Franklin Institute, and a special gold medal from the Photographic Society of Philadelphia.

We are informed that a company in this city under the style of "Ives Inventions" is soon to introduce this latest system, which seems to be of a very practical character.

\title{
WIRELESS TIME SIGNALING TO SEA FROM THE EIFFEL TOWER
}

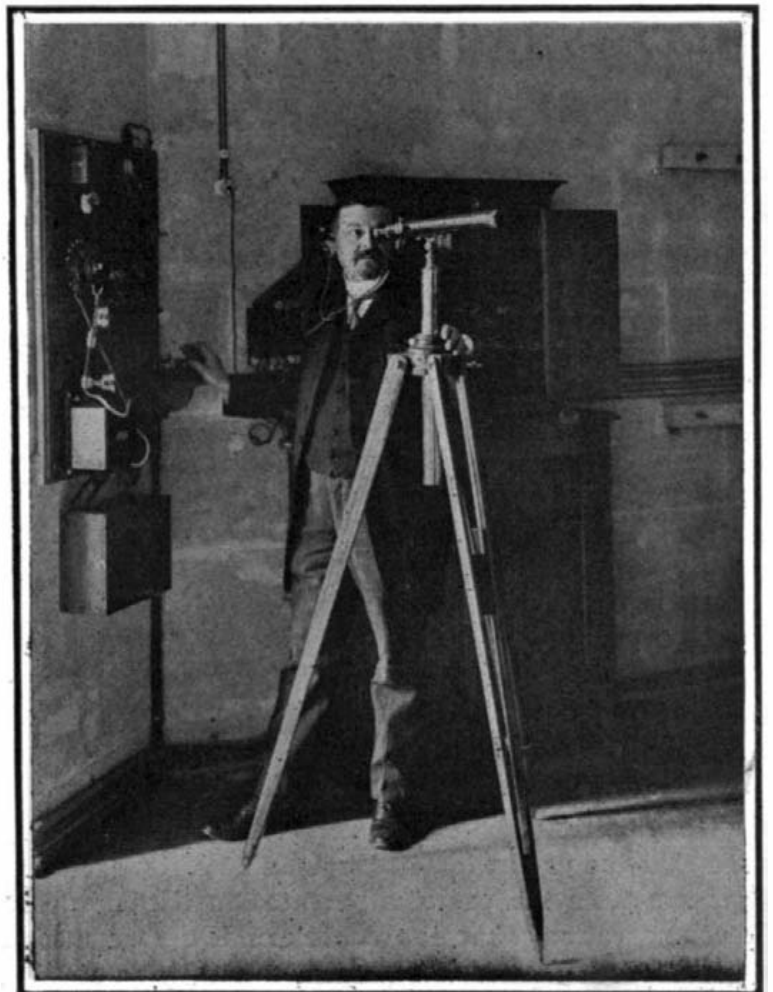

WATCHING THX PENDULUX THBOUGH THB TELESCOPE.

\section{B Y F. HONORE}

The wireless telegraphic station of the Eiffel Tower is now signaling Paris Observatory time to all vessels within a radius of 1,800 miles. The present station is using 15 to 16 horse-power. When the new installa tion, whose completion was delayed by the recent floods, is finished, 100 horse-power will be at the dis posal of the engineers, and the range will be doubled.

A master clock, which has long been used for the correction of marine chronometers, is set up in a room of the observatory, side by side with clocks that telegraph mean time to various centers in Paris, and sidereal clocks which serve to regulate this mean time. The master clock in question itself indicates mean time with reference to the meridian of Paris. Inclosed in a glass case, and suspended from a wall so thick that vibrations in masonry and variations in temperature cannot affect the mechanism, it is corrected each day, if necessary, by means of a magnetic regulator. The rod of the pendulum carries a magnet, the lowe end of which is spaced a few millimeters from a solenoid. Depending upon the direction of the current which is sent through the solenoid, the magnet is at tracted or repelled, thus retarding or accelerating the beat of the pendulum. In this manner a lost second is regained in thirty-six minutes.

The clock is connected by wires with the key of the wireless station of the Eiffel Tower. At midnight, at 12:02, and at 12:04, the clockwork automatically

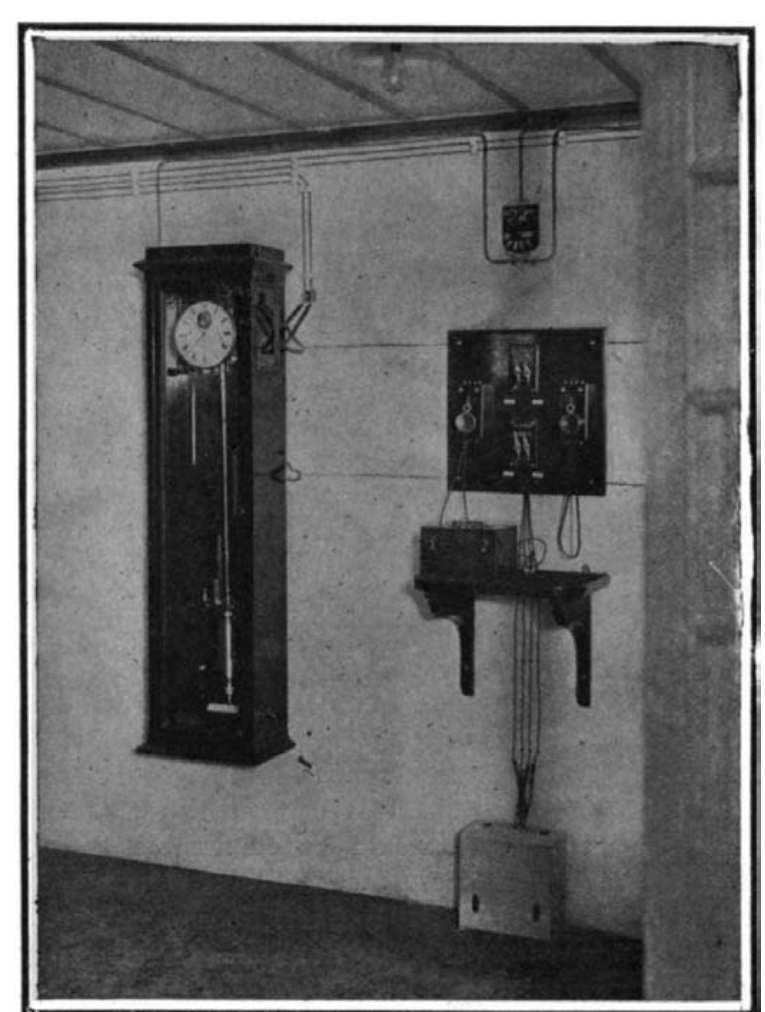

CLOCK WHICH AUTOYATICALLY TELEGRAPHS TIME. 
completes a circuit, thus actuating a Morse key and causing Hertzian waves to be emitted.

The observatory itself is not equipped to send wireless signals, but it receives them by means of a small aerial connected with telephonic receivers. On the other hand, by means of a Morse key in the circuit of an ordinary telegraph system, independent of the clock, the wireless apparatus on the Eiffel Tower can be operated from the observatory.

At the proper time each day, an official dons a telephone headpiece, and proceeds to the work of notify.

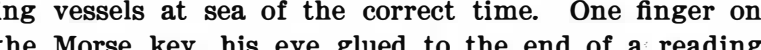
telescope, the official watches the beat of the pendulum. At 11:59 he depresses the key, and by means of agreed signals, he attracts the attention of vessels in the range of action. At midnight, the clock automatically signals the hour. This transmission of time is repeated twice, as we have said, namely, at 12.02 and at $12: 04$, preceded by other combinations of warning sig nals. Hence vessels receive the time thrice in five minutes.

The officer on board the vessel at sea is similarly equipped with a telephone headpiece, and he watches a chronometer instead of a clock. Making due allowance for possible errors of observation, he estimates the error of his chronometer.

\section{Esperanto and Ido.}

In last week's Scientific American Supplement we chronicled the fact that a new international language has made its appearance, which is a strictly scientific attempt made by an international commission of philosophers, scientists, and pilologists to improve Esperanto and to provide the world with an artificial language which shall be truly international. Some of our Esperantist friends have misunderstood the purpose of the commission, and do not fully realize the scope of the improvement which has been effected. They have written rather heated protests against the article which we published. We are neither Esperantists nor Idoists, but it seems to us that a fair examination of the International Commission's work must convinee anyone of the valuable service which it rendered. Below we republish Prof. O. Jespersen's views of the limitations of Esperanto, taken from a recent book published by the Délégation pour l'adoption d'une langue auxiliaire internationale:

"Dr. Zamenhof has given us an interesting account of the way in which his language gradually developed in his mind while he was at the Warsaw Gymnasium. Before he arrived at the conviction that the material for the vocabulary must be obtained from the Romance and Germanic languages, and that the already existing stock of international words must be used, he had 'simply invented' his words, that is to say, chosen them quite arbitrarily, but with as much regard to system and brevity as possible. Although he himself noticed that such words are difficult to learn and still more difficut to remember, he has unfortunately re tained in the finished language a whole series of such d priori formations, which appear in words of such frequent occurrence as 'who,' 'how,' 'where,' 'never,' 'everywhere,' etc. The 'nul tempe' and 'pro quo' chosen by the Delegation agree, however, much bet ter with the general character of language than the 'neniam' and 'kial' of Dr. Zamenhof.

"Some peculiarities may be accounted for by the Slavonic mother tongue of the author: for example, his preference for sibilants and diphthongs, which is especially evident in the invented words (e. g. chi, here; chiu, each; ech, even; ghi, that; ghis, until, gh and $c h$ being pronounced as E. $j$ and $c h$ ). In an article in Zamenhof's Krestomatio I find, for example (p. 288) chiuj tiuj senantaujughaj kaj honestaj homoj, kiuj, anstatau filizofadi pri ghi, and (p. 293) tion chi ankorau antau la apero de la unua arta lingvo antauvidis kaj antaudiris chiuj tiuj eminentaj kapoj, kiuj, etc. The method of writing ' $x$ ' is also Russian ekzameni, ekzemplo, etc., and also ekspedi, eksplodi, also $k v$ for $q u$. French words with $o i$ take $u a$ in Esperanto when they are spelt in this way in Russian, e. g. trotuaro, tualeto, vuala; othe they are spelt with oi or oj, e. g. foiro, fojo, foino. Nacio, tradicio etc., instead of -iono, is also Russian. Russian usage has doubtless also inspired such word formations as elparoli and senkulpigi instead of the international pronuncar and exkuar (Russian vygovarivat' and izvin'at', corresponding to German aussprechen and entschul digen). The peculiarity of using the adverb instead of the adjective in such cases as estas necese vidi, 'it is necessary to see,' is probably to be ascribed to the correspondence of the Russian adverb with the neuter predicate adjective. This rule cannot be permitted, however, in an international language, because, with a free word order, it would be impossible to say whether estas vere necese means 'it is really neces sary,' or 'it is necessarily true.' The compound per fect ( mi estas aminta, 'I have loved' = 'I am having love') reminds one of the Polish kechal-em. Finally, the frequent use of the adjective (In -a) instead of the genitive (Zamenhofa ungvo) and of the two sorts of action expressed by $e k$ and $a d$ (ekvidi-and vidad used in many cases where the simple vidi would be sufficient), are to be accounted for by Russian usage "Naturally I do not object to the importation of national peculiarities into the international auxiliary language when the latter is enriched thereby. Fo example, one must make use of the facility for forming compound words common to the Germanic and Slavonic languages in preference to the poverty of Romance languages in this respect, and combine with the more Romance characteristic of forming new words by means of derivative syllables. But peculiari ties of national language which render mutual comprehension and internatio

"The unpractical nature of the circumfiexed letters has been indicated. It may be remarked here, how ever, that in point of system Zamenhof's letters are very inferior to the similar ones employed in the Czech language, since the parallelism in sound be tween $s$ and $\hat{s}, z$ and $\hat{j}, d z$ and $\hat{g}$, is disguised by the choice of letters. This produces a very amateurish effect.

"Beside the familiar parts of speech which are in dicated by special terminations, Zamenhof invented new class characterized by the termination -au (kon trau, almenau); but the limits of this class, which includes some, but not all, adverbs and prepositions, are not clearly defined.

"Many words taken from existing languages are dis guised, almost after the fashion of Volapük; $b o j$ French aboyer; parkere, French par cœur; schvit, German schwitzen, English sweat; char, French car faruno instead of farin; lerta, French alerte (with a changed meaning), etc. In this category is to be classed the astonishing nepre (entirely) which is de rived from the Russian nepremenno, just as if one were to take from the German word unbedingt the first two syllables and propose unbe as an intern tional word instead of absolute. The economy in the use of stems was carried much too far in Esperanto, necessitating the employment of all sorts of com pound words, the discovery of whose meaning $r$ quires much racking of one's brains. The employment of all the derivative syllables also as independ ent words is very ingenious, but produces a very strange impression on the uninitiated.

"The method of word formation is greatly wanting in precision, the limits of the so-called direct derivation in particular being not sufficiently clearly indicated. One example will suffice. Starting out from kroni $=$ to crown, krono ought properly to mean crowning, instead of which it signifies crown, so that one is forced to use kronado for crowning, whereas, according to the rules of Esperanto, kronado must mean continuous or repeated crowning, as if a king were being constantly or repeatedly crowned.

"I have brought together here the most important defects in Esperanto, the removal of which formed one of the tasks of the Delegation Committee. The knowledge of these imperfections does not prevent me from recognizing the meritorious services of Zame hof, who, at a time when the question of the best construction of an international language was not seriously discussed, succeeded in producing one which was in many respects superior to the attempts of that time, and which has proved in practice a serviceable, though very imperfect, means of international communication."

\section{The Government and the Invento}

We recently commented upon a bill which is being Considered by the House of Representatives, the purpose of which is to compensate those inventors whose inventions have been appropriated by the government. Since the publication of our remarks, further testimony has been taken before the Committee on Patents, which reveals the hardships of an inventor who endeavors to create something which will be of benefit to his Government, which only the Government can use, and for which he has only one customer, and that is the Government itself.

One such invention is a torpedo system with a trolley guide, which was conceived by $\mathrm{Mr}$. William $\mathrm{S}$. Brewster, while he was associated with Mr. Edison. It was at the time Mr. Edison and Gardner Sims were perfecting the Edison-Sims torpedo. Mr. Brewster thought that inștead of guiding the torpedo to its destination by its own mechanism, it could be guided by a trolley system. He consulted Generals Newton New York, who were then prominent engineers in patent out until advised to do so by a prominent officer in the War Department. In 1896 he applied for a patent, which was issued in 1897 , and which was offered to the War Department at practically the Department's own terms. The patent was granted for an invention which Mr. Brewster could not use himself and which the Government might use if it found it serviceable. The offer was declined. In 1898, at the time of the Spanish war, the Invention was again offered to the Government, with the understanding

that any reasonable remuneration would be accepted. In June, 1908, it was announced that the Navy Department was going to test a new trolley-controlled torpedo off Fortress Monroe, against a modern battleship to note the effect. Immediately before the test took place Mr. Brewster wrote to the Navy Department and inclosed a copy of his patent, and a bill for the use of his patented trolley system in this torpedo test at Hampton Roads. In so far as the Government used his trolley to guide the torpedo so that it should strike the target, Mr. Brewster thought that it appropriated his invention. One of Mr. Brewster's claims reads:

"In a submarine torpedo system, a submerged cable constructed and adapted to constitute a track for guiding and controlling a torpedo in transit, and a torpedo connected thereto, substantially as set forth."

This is so broad that the Government obviously infringed.

The trolley system has since been used in testing the Davis torpedo gun. Mr. Brewster wrote again to the Navy Department asking for compensation for the use of his invention. The Navy Department replied that the Electric Boat Company was making the tests of the Davis torpedo, although, as a matter of fact, the contests were actually conducted by officers of the navy. Lieut. Commander Davis acknowledged the use of the guide, saying that he did not know of the patent. Further correspondence with the Navy Department led to a controversy on the scope of the patent and the price demanded, and finally ended in a fiat refusal to pay.

Another shining example is to be found in the utiliation by the Government of Prof. R. A. Fesser mprovements in wireless communication. Prof. Fes senden was employed for about a year in the Weather Bureau. One or two of his early inventions were produced during his employment, but all of his later ones have been produced since. Some of his patents have been the subject matter of suits in the Circuit Court of the United States and have been sustained. In fringements of them have been enjoined. The unsuccessful defendant in one suit tendered infringing wireless material to the Navy Department Prof. Fessenden protested against the Navy Department's purchasing the material from the infringer, calling its attention to the fact that a court of the United States had enjoined it from furnishing such material. The Department replied, rather autocratically, that, however that might be, it preferred to purchase material in the cheapest market and leave it to the patentee and in fringer to work out their salvation as best they could. The infringer proceeded to furnish the material contracted for and delivered it to the Navy Department. The furnishing of that material was used as the basis for contempt proceedings. The officers of the infringing company

There is now pending in the Supreme Court on writ of certiorari a case brought in the local court by the Krupp Company against General Crozier, Chief of Ordnance, in which it asks for an injunction to restrain him and his subordinates from making guns for the army according to the Krupp patent. When the case came up for decision in the Court of Appeals of the District of Columbia, the Court held that regardless of the fact that General Crozier was an officer of the United States army, he derived no personal benefit from the use of the Krupp patents, nevertheless, he was an infringer. The Krupp Company asked only for an injunction in this case, and not for any compensation for the use made of its patent prior to the final decree. An injunction pure and simple would not be a complete remedy in many cases. General Croier was merely the agent of the Ordnance De partment. The Government of the United States derived the benefit and not he from the use of the Krupp inventions. But that situation does not absolve the Government from paying.

Very often, patents are being infringed by the Gov ernment without the knowledge of the patentee, be cause not every one can walk into a naval gun shop and see what is going on. Machines may be used in the Post Office for years without the fact being dis covered. A man may invent a new brand of chewing gum or a child's game and make a fortune. He may invent a useful gun or gun carriage, or a new style of armor, or a useful device in the Post Office that would save a great deal of money to the postal service, and get nothing at all for his time and labor excep at the caprice or whim of some Government officer.

So hard have been some of the cases that it must 
vidual or corporation. Yet the Government ignores that decision and refuses to pay.

Hence such actions as inventors have succeeded in sustaining against the United States have been largely based upon implied contracts. Thus in Burns's case (12 Wall, 240) it was held that the offer of the Government to use a patented invention was a valid consideration to support an action on an express contract for royalty. At first sight, it might seem as if patentees already have protection in the remedy which they now have in the Court of Claims for the infringement of their rights by the Government. The courts have, however, found a difficulty standing in the way of granting to inventors a right to damages against the Government in cases where their patents have been used, in the fact that the statutes defining the jurisdiction of the Court of Claims confine it as a rule to cases arising upon contract with the Government. Hence the necessity of bringing actions under contracts implied or expressed. Thus, in the case of Palmer (128 U. S., 262), the patentee invited the Government to adopt his invention, and the Government did so. This was held to amount to an implied contract. In the case of the Berdan Fire Arms Company (156 U. S., 552) the patentee communicated his invention to the officers of the Government, and they used it without expressly repudiating his title. These facts were held to give rise to the implication of a contract. The line is so slight as to be little more than fortuitous, and the distinction is one that is utterly unworthy of a great govern

\section{New Trade Mark Bills.}

As the trade mark law now stands, the registration by a corporation of a technical trade mark which may be its whole name or part of its name is impossible. The Court of Appeals has held in a recent decision published in the Official Gazette of July 7th, 1908, in the case of Kentucky Distilleries and Warehouse Company vs. Old Lexington Club Distilling Company, that where the applicant is a corporation, a trade name where the applicant is a corporation, a trade name
which is substantially a reproduction of the corporate name cannot be registered as a technical trade mark. That decision was regarded by the Patent Office as authority for making further decisions which are generally known in the profession as the decision in the case of the Champion Safety Lock Company, the Amulet Chemical Company, the Union Carbide Company, and the Success Company.

The situation is anomalous. The Champion Safety Lock Company could not register its trade mark "Champion" under the law as it now stands, or as it is now interpreted by the Court of Appeals, because the word "Champion" is a conspicuous or salient part of the name of the company, while John Smith, who has no rights whatever with regard to the Champion mark, may register the trade mark. Obviously, this is unjust. A bill has been introduced for the express purpose of authorizing the Patent Office to grant such marks and to follow the letter of the law.

In cases such as the Union Carbide Company case there is, however, another element which must be considered. In this case the word "Union" may be regarded as geographical, and "Carbide," of course, as descriptive, so that possibly this is a case where the trade mark should not be registered unless it came under the ten-year clause of the law. But "Success" and "Champion" and "Amulet"

Another instance can be found in the word "Kodak" as applied to photographic cameras. That word is undoubtedly a good trade mark. It has been sustained by courts of this country and courts abroad.

Yet it is ineligible to registration because the company that explcits the manufacture of that particular thing and has the ownership of that mark, has come to be called the "Eastman Kodak Company." It seems unfair that a trade mark which is a good mark should be unregistrable because it happens to be in corporated in the firm name or the corporate name of its owner.

The Committee on Patents of the House of Representatives has also before it for consideration measures which have for their purpose the increasing or facilitating of remedies for trade mark infringement, enabling the Patent Office to keep a more complete record of trade mark claims or rights:

The change proposed in one of the bills permits the registration of non-technical marks if it can be alleged in the application that to the best of applicants knowledge and belief the marks have been used for ten years prior to the filing of the application. The present law reads "ten years prior to the passage of the act," which was February 20th, 1905. Consequently, merchants who adopted marks in 1896 cannot to-day register them under the ten-year clause of the law, altrough they have used the marks for about fourteen years. It is perfectly fair to assume that after the mark has been used for ten years, it has become distinctive of the goods. The measure ought to be passed.

\section{(U)}

\section{DISTILLING LICENSES.}

To the Editor of the Scientific American:

I have seen in one of your Scientific American publications an article concerning "Manufacturing Perfumes at Home." You recommend a still for the distillation of fiowers; also illustrate such a still. wish to call your attention to the fact that such still must be registered with the collector of the district in which such still is located, not only before operation begins, but immediately after the still comes into the possession or custody of such person, whether it be a new still, distillery apparatus, or not.

The law requires all stills set up to be registered if for use or not. This applies to all stills, of what ever size and for whatever purpose intended. Any still which is not registered is subject to forfeiture to the United States, together with all personal property in the possession or custody or under the control of such person and found in the building or in any yard or inclosure connected with the building in which the same may be set up. The person whose duty it is to register any still, failing to do so, is subject to fine and imprisonment under section 3258 Revise Statutes (Internal Revenue Department).

Kindly bring this to the attention of your subscribers to avoid any difficulties.

Newark, N. J. H. H. FreUnd.

\section{RAISING THE "MAINE."}

\section{To the Editor of the Scientific American}

The recent act of Congress authorizing the raising of the wreck of the U. S. S. "Maine" has given rise to many suggestions for raising her. The wreck ha rested on the bottom of Havana harbor for nearly twelve years, and has doubtless settled considerably in the mud. The "Maine" was destroyed by the explosion of a submarine mine, which caused the partial explosion of two or more of the forward magazines. Apart from the loss of life, the results of this explosion were that the vessel from the bow to frame 41 was terribly shattered.

Therefore it can be said that the "Maine" from frame 41 aft is structurally sound, although it is doubtful if anything could be done to repair the shat tered forecastle. The debris of the bow could be destroyed by dynamite, and the afterpart raised.

A new bow would then have to be constructed, which could be later joined to the old afterpart. similar thing was accomplished in 1907, when th White Star liner "Suevic" was wrecked off the English coast. Her afterpart was separated from the bow, which was held fast by the rocks, and she proceeded under her own steam to Southampton, where she wa docked. A new bow 212 feet long was built at Belfast, towed to Southampton, and joined to the vesse Within a year the "Suevic" was able to resume he regular duties as one of the White Star Line's Aus tralian steamers.

rooklyn, N. Y.

\section{HOW LARGE DOES THE SUN APPEAR TO BE?}

To the Editor of the Scientific American:

Ask ten people how large the sun looks to them when it is in mid-heaven, and you will get ten dif ferent opinions of its size, which range from a silve to the fact that there is nothing with which to com pare it when looked at by itself. Before any accurate estimate of its size can be made, we must have some known object with which to compare it.

Thus, when the sun is on the horizon and appears to be close to houses, trees, and hills, it looks ver or tree. Moreover, there are more persons who will agree that it appears to be a certain fixed size under this condition than will agree when it is viewed a the zenith. The diversity of opinion in the latter cas results from the inability of the eye to "size up" an isolated object.

This has been proved by projecting a narrow beam of light on a perfectly black, non-reflecting screen so placed that the observer could see nothing but the beam of light and had no way of judging his distance from the screen. The observations of several people under these conditions revealed the fact that there was no certainty about the length of the beam, the apparent length being estima

This being the case when the sun is in mid-heaven This being the case when the sun is in mid-heaven,
how can its size be reduced to some uniform standard?

The most logical answer is found by representing it as a circle located at a fixed distance from the eye The average reader holds the printed page about on he can estimate for reading. At this distance he can estimate fairly closely the size of the type or
an illustration. In fact, a dozen good judges of dimensions can tell the size of an illustration, that doe not exceed a few inches, within a small fraction of

an inch. These same men, if asked to draw a circle on the sheet that would just cover the sun's disk if held between them and the sun at a distance of one foot from the eye, would produce a series of circles of magnitudes ranging from a twenty-five cent piece to a saucer.

The real size of the circle should be only threeTeenths of an inch in diameter.

The method of representing the sun's exact size by a circle one foot from the eye is simple. Take a smoked glass, hold it one foot from the eye and scratch pin marks tangent to the sun's disk at the four quarters. When the diameter of the circle inclosed within these marks is measured, it will be found to be very close to three-sixteenths of an inch. In other words, if a circle of this size were drawn, and in its area were reproduced in proportion to an average sun spot, the observer would be able to examine the small dot at a distance of one foot from his eye with just about the same ease that he could examine the real spot on the sun through a smoked glass. Or, again, if the moon, which is the same apparent size as the sun, and whose disk can be represented by the same small circle, were to be reproduced in miniature within its area, an observer holding it one foot from his eye could examine it with the same scrutiny that he could examine the full moon with his naked eye.

Detroit, Mich.

E. C. Landis.

\section{The Current supplement.}

The British Antarctic expedition has started on its journey for the South. Consequently the opening article of the current SuPPLEMENT, No 1798, in which the equipment of the expedition is described, will prove of interest. Not so many years ago, in his famous book on education, Herbert Spencer put forth a powerful plea for the study of science. Nowadays, however, an advocacy of that kind is not called for, and his book is at present largely of historic value only. Since that time the pendulum has been swinging too far toward the scientific. Prof. Albert G. Keller, in an article on Science and the Humanities, argues for the inevitableness of the humanities and of humanity. He asserts not only that our lives may be enriched by the pursuit of culture in diverse forms; not only that our destinies must be impoverished by the renunciation of all lines save one, but also insists upon the more concrete contention that our special scientific work is bound to suffer as a consequence of the neglect of that for which the humanities stand. In all parts of the civilized world, the least desirable element in the population, from a physical and mental standpoint, is producing more numerous progeny, and it would seem that unless means can be devised to stay this fiood of the unfit, in the course of time the entire race must descend to a lower level as regards physical and mental qualities. Of late, the aid of eugenics and more recently still, that of Mendelism, has been invoked to keep the race at a high standard. The methods adopted are outlined in an article entitled "Eugenics and Mendelism." Mr. Paul F. Bauder writes instructively on the quality of light. A sympathetic and appreciative biography is published of the late Sir William Huggins. Elihu Thomson contributes a thoughtful paper on atmospheric electricity. One of the most interesting problems of archæology has been solved by the recent excavations at Arlesia, that ancient city of Gaul where Vercingetorix headed 80,000 of his countrymen in a last gallant, though futile attempt to stem the advance of the victorious legions of Cæsar. The wonders of these excavations are told in an interesting article. Mr. Leon A. Hackett contributes a very exhaustive paper on the processes of cotton spinning.

The removal of ashes by conveying them to a waste bank hydraulically is done in connection with the temporary plant built to supply power during the construction of the Kainbow Falls hydro-electric development of the Great Falls Water Power and Townsite Company on the Missouri kiver, near Great Falls, Mont. The power house is on the side of a hill directly above the edge of the river bank. The bituminous coal used is dumped by gravity from cars on a trestle to a bin at the rear of the firing floor of the boiler-room, and runs down on this floor, from which it is fed by hand to the furnaces. As the ashes fal through the grates they are drawn out into a transverse concrete-lined trench in the firing fioor. This trench is sloped to one side of the building, where 